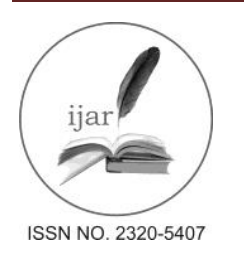

Journal homepage:http://www.journalijar.com
Journal DOI:10.21474/IJAR01

\section{RESEARCH ARTICLE}

\title{
HAPTOGLOBIN PHENOTYPE, HP1-1: A POTENTIAL RISK FACTOR OF BREAST CANCER IN GHANAIAN WOMEN.
}

\section{Emmanuel A. Tagoe ${ }^{1}$, Patience Aglago ${ }^{1}$, Benjamin Arko-Boham ${ }^{1}$, Nii Ayite Aryee ${ }^{2}$, Josephine Nsaful ${ }^{3}$, Richard Harry Asmah ${ }^{1}$ and Joe-Nat Clegg-Lamptey ${ }^{3}$.}

1. Department of Medical Laboratory Sciences, School of Biomedical and Allied Health Sciences, College of Health Sciences, University of Ghana.

2. Department of Medical Biochemistry, School of Biomedical and Allied Health Sciences, College of Health Sciences, University of Ghana

3. Department of Surgery, University of Ghana School of Medicine and Dentistry, College of Health Sciences, University of Ghana.

\section{Manuscript Info}

Manuscript History:

Received: 15 May 2016

Final Accepted: 19 June 2016

Published Online: July 2016

Key words:

Haptoglobin phenotypes, breast cancer, chemotherapy,

Polyacrylamide gel electrophoresis, treatment.

*Corresponding Author

Emmanuel A. Tagoe

\section{Abstract}

Background:- The haptoglobin phenotypes association with diseases is widely studied. However, association of the phenotypes with breast cancer especially in patients of African descents has received little attention.

Aim:- To determine the association of haptoglobin phenotypes with breast cancer among Ghanaian patients.

Methods:- A total of 63 women diagnosed with breast cancer and 54 female controls were recruited. The participants were between the ages of 20 and 60 years. Demographics and clinical parameters were collected. Polyacrylamide gel electrophoresis was used for haptoglobin phenotyping employing serum haemoglobin-supplementation method.

Results:- Hp 1-1 and HP 1 allele frequencies were high among patients. Hp $1-1$ was strongly associated with breast cancer $(\mathrm{OR}=3.09, \mathrm{CI}=1.32-7.24$, $\mathrm{p}=0.014)$ than Hp2-1 $(\mathrm{OR}=2.1, \mathrm{CI}=0.88-4.58, \mathrm{p}=0.139)$ and Hp 2-2 $(\mathrm{OR}$ $=0.24, \mathrm{CI}=0.10-0.54, \mathrm{p}=0.0008)$. Most of the patients were traders $(55.5 \%)$ and $22.2 \%$ were below the age 40 years. Blood pressure was elevated in patients than controls $(\mathrm{p}<0.05)$ but difference was not significant when patients on chemotherapy was compared with those without treatment ( $\mathrm{p}>$ 0.05 ). However, body mass index was significantly raised in patients and was independently affected by chemotherapeutic treatment but not age $(\mathrm{p}<0.001)$. Conclusion:- The strong association of haptoglobin phenotype, Hp 1-1 with breast cancer may suggests a critical role of the protein in disease prognosis.

Copy Right, IJAR, 2013, All rights reserved.

\section{Introduction:-}

Breast cancer (BC) is rated high among cancers in women and found to be the leading cause of cancer related deaths globally. The aetiology of BC is not immediately known but factors including age, early stage at menarche, late age at first child birth, family history, oral contraception and increased age at menopause have been suggested to play a critical role (Babita et al., 2014). Breast cancer incidence is high especially in the developing countries and late presentation to health facilities has been attributed to several factors (Clegg-Lamptey et al.,2009). In most cases, patients present the disease at the advanced stage and that poses a challenge to management leading to poor prognosis. Progression of $\mathrm{BC}$ has been associated with tumour microenvironmental alterations and is increasingly recognized as a major regulator (Jerby et al., 2012). Identified biological signatures that influence tumour microenvironment in patients could be useful in the prediction of disease outcome. 
Haptoglobin, an acute phase circulatory protein has been associated with many diseases including breast cancer (Awadallah and Atoum, 2004). Haptoglobin gene locus is highly polymorphic with two common co-dominant HPl and HP2 alleles. The two alleles produce three distinct phenotypic presentations, Hp1-1, Hp2-1 and Hp2-2 (Sadrzadeh and Bozorgmehr, 2004) with occasional modified Hp2-1 (Hp2-1M) (Maeda, 1991). The effectiveness of physiological function depends on the phenotype and has been implicated in several diseases (Zhao et al., 2007; Abdullah, 2009). The weak antioxidant property of Hp2-2phenotype has been implicated in several diseases (Quaye et al., 2006; Vormittag et al., 2005). However, Hp1-1 has been associated with breast cancer (Awadallah and Atoum, 2004). In cancers, the antioxidant/oxidant system is altered in favour of the later to sustain disease progression (Warburg, 1956). Reduced level of lipid peroxidation in serum of breast cancer patients has been reported, suggesting elevation or presence of effective antioxidants (Gerber et al., 1996; Gonenc et al., 2006).

To our knowledge no data exist on the association of haptoglobin phenotypes and breast cancer in Ghanaian patients. The aim of the study was to determine the prevalence of haptoglobin phenotypes and their association with breast cancer in Ghanaian patients.

\section{Methodology:-}

\section{Study design:-}

The study was a case-control study and was carried out from April to August, 2015.

\section{Study site:-}

Breast cancer patients were recruited from the Department of Surgery, Korle Bu Teaching Hospital, Accra-Ghana and controls from women group. The haptoglobin phenotyping was carried out at the Department of Biochemistry, Cell and Molecular Biology, Legon, University of Ghana.

\section{Study population and sampling:-}

Female patients diagnosed with breast cancer and apparently healthy female controls were recruited into the study. Clinical history, mammogram and histopathological investigations were the diagnostic procedures. Patients on chemotherapy, hormonal treatments and newly reported were recruited consecutively while the controls were recruited from a community using standard questionnaire. Patients diagnosed with other types of cancers were excluded from the study and all participants gave a written consent. The study was approved by the Protocol and Ethical Review Committee, School of Biomedical and Allied Health Sciences, University of Ghana.

\section{Anthropometrical and blood pressure measurements:-}

Height and weight of participants were taken and body mass index (BMI) calculated. Mercury sphygmomanometer with stethoscope were used to measure the blood pressure after allowing the participants to rest for 15-20 minutes on arrival. The blood pressure was taken twice with 2-5 minutes interval and the average was calculated. Other sociodemographic data collected include age, occupation and body surface area (BSA).

\section{Sample preparation:-}

About $5 \mathrm{ml}$ of venous blood was collected from the arm of each participant and dispensed into serum gel separator tube. Blood sample in gel separator tubes were centrifuged and serum aliquoted into Eppendorf tubes. Serum was stored at $-20^{\circ} \mathrm{C}$ for later use.

\section{Determination of haptoglobin phenotypes:-}

Serum haptoglobin phenotypes were determined by discontinuous polyacrylamide gel electrophoresis (PAGE) with haemoglobin-supplementation followed by 3,3,5,5-tetramethyl benzidine with o-dianisidine staining.

\section{Statistical analysis:-}

SPSS 20.0 version was used for the analyses. Means and standard deviations (Mean \pm SD) were used to summarize all quantitative variables. Student's unpaired t-test was used to compare mean values. Chi square $\left(\chi^{2}\right)$ was used to comparison proportion and Odds ratio (OR) for association. $\mathrm{P}<0.05$ was considered statistically significant for all analyses. 


\section{Results:-}

The comparison of the demographics and clinical parameters of the studied population is shown in Table 1. A total of 117 volunteers took part in the study and were made up of 63 breast cancer patients and 54 apparently healthy controls. The clinical parameters; systolic blood pressure (SBP), diastolic blood pressure (DBP) and body mass index (BMI) were significantly raised in the patients than the apparently healthy controls $(\mathrm{p}<0.05)$. The occupation distribution between the patients and the apparently healthy control was not statistically significant $(p=0.264)$. In the current study, equal number of left and right breast cancers were presented. Body mass index strongly correlated with both systolic $(r=0.366, \mathrm{p}<0.001)$ and diastolic $(\mathrm{r}=0.296, \mathrm{p}<0.001)$ blood pressure of the patients.

Table 1:- Socio-demographics and clinical parameters of the studied population.

\begin{tabular}{|c|c|c|c|c|}
\hline Parameter & $\begin{array}{l}\text { Breast Cancer Patients } \\
\qquad(\mathrm{N}=63)\end{array}$ & $\begin{array}{l}\text { Control } \\
(\mathrm{N}=54)\end{array}$ & $\begin{array}{c}95 \% \text { CI } \\
\text { of mean diff. }\end{array}$ & $\begin{array}{l}\text { p-value } \\
\text { (t-test) }\end{array}$ \\
\hline Age (yrs) & $48.84 \pm 10.58$ & $42.26 \pm 14.37$ & $2.00-11.63$ & $0.005^{*}$ \\
\hline BMI $\left(\mathrm{kg} / \mathrm{m}^{2}\right)$ & $30.13 \pm 6.43$ & $26.44 \pm 5.53$ & $-5.91-(-1.47)$ & $0.001 *$ \\
\hline $\mathrm{SBP}(\mathrm{mmHg})$ & $133.25 \pm 21.07$ & $121.15 \pm 15.91$ & $5.18-19.04$ & $0.001 *$ \\
\hline DBP (mmHg) & $79.79 \pm 11.70$ & $74.37 \pm 11.70$ & $1.80-9.05$ & $0.004 *$ \\
\hline $\mathrm{BSA} / \mathrm{m}^{2}$ & $1.83 \pm 0.20$ & - & - & - \\
\hline Occupation $\mathrm{n}(\%)$ : & & & $\chi^{2}$ & \\
\hline Trader & $35(55.5)$ & $36(66.7)$ & & \\
\hline Civil servant & $7(11.1)$ & $8(14.8)$ & & \\
\hline Fashion industry & $5(7.9)$ & $2(3.7)$ & 5.24 & 0.264 \\
\hline Unemployed & $7(11.1)$ & $6(11.1)$ & & \\
\hline Unskilled labour & $9(14.3)$ & $2(3.7)$ & & \\
\hline
\end{tabular}

Comparison of the clinical parameters between patients on chemotherapeutic treatment and those without treatment is presented in Table 2. Both blood pressures showed no significant difference ( $\mathrm{p}>0.05)$. Nevertheless, body mass index was significantly increased in patients on chemotherapy than the treatment naïve patients $(\mathrm{p}<0.05)($ Table 2$)$.

Table 2:- Comparison of breast cancer patients receiving chemotherapy with patients without treatment.

\begin{tabular}{lcccc}
\hline Parameter & $\begin{array}{c}\text { Chemotherapy } \\
\text { treatment } \\
(\mathrm{n}=19)\end{array}$ & $\begin{array}{c}\text { Patients } \\
\text { without treatment } \\
(\mathrm{n})=16)\end{array}$ & $\begin{array}{c}95 \% \text { CI } \\
\text { of mean diff. }\end{array}$ & p-value \\
\hline Age $(\mathrm{yrs})$ & $47.50 \pm 7.26$ & $49.16 \pm 9.48$ & $-4.24-7.55$ & 0.571 \\
BMI $\left(\mathrm{Kg} / \mathrm{m}^{2}\right)$ & $32.50 \pm 5.64$ & $28.65 \pm 4.34$ & $-7.28-(-0.42)$ & $0.029^{*}$ \\
SBP $(\mathrm{mmHg})$ & $136.75 \pm 22.67$ & $134.47 \pm 18.29$ & $-16.36-11.81$ & 0.744 \\
DBP $(\mathrm{mmHg})$ & $76.69 \pm 10.76$ & $136.75 \pm 22.6$ & $-2.99-11.84$ & 0.234 \\
\hline
\end{tabular}

Patients on chemotherapy received had no other interventions. BMI = body mass index, $\mathrm{SBP}=$ systolic blood pressure, $\mathrm{DBP}=$ diastolic blood pressure $* \mathrm{p}$ - value is statistically significant.

The most frequent tumour stage and grade were T4 and grade II and $77 \%$ of the patients were above 40 years (Table 3). The common treatments were chemotherapy (Cyclophosphamide, Adriamycin and 5-Fluorouracil) and hormonal treatments (Tamoxifen or Arimidex) while $25.4 \%$ were new cases. 
Table 3:- Age-stratification of pathological descriptions and treatments of breast cancer patients.

\begin{tabular}{|c|c|c|c|c|}
\hline Description & & $\begin{array}{c}\text { All } \\
\mathrm{N}=63\end{array}$ & $\begin{array}{c}<40 \text { yrears } \\
\mathrm{N}=14\end{array}$ & $\begin{array}{c}>40 \text { years } \\
\mathrm{N}=49\end{array}$ \\
\hline Affected breast & $\mathrm{n}(\%)$ & & & \\
\hline Left & & $29(46.0)$ & $7(50.0)$ & $22(44.9)$ \\
\hline Right & & $32(50.8)$ & $7(50.0)$ & $25(51.0)$ \\
\hline Both & & $2(3.2)$ & $0(0.0)$ & $2(4.1)$ \\
\hline Tumour stage & n (\%): & & & \\
\hline $\mathrm{T} 1<2.0 \mathrm{~cm}$ & & $2(3.2)$ & $0(0.0)$ & $2(4.1)$ \\
\hline $2<\mathrm{T} 2<5 \mathrm{~cm}$ & & $9(14.3)$ & $2(14.3)$ & 7 (14.3) \\
\hline $\mathrm{T} 3 \geq 5 \mathrm{~cm}$ & & $13(20.6)$ & $3(21.4)$ & $10(20.4)$ \\
\hline $\mathrm{T} 4>>5 \mathrm{~cm}$ & & $32(50.8)$ & $8(57.2)$ & $24(49.0)$ \\
\hline Unknown & & $7(11.1)$ & $1(7.1)$ & $6(12.2)$ \\
\hline Tumour grade & n $(\%):$ & & & \\
\hline Grade I & & $15(23.8)$ & $3(21.4)$ & $12(24.5)$ \\
\hline Grade II & & $28(44.4)$ & $4(28.6)$ & $24(49.0)$ \\
\hline Grade III & & $17(27.0)$ & $7(50.0)$ & $10(20.4)$ \\
\hline Unknown & & $3(4.8)$ & $0(0.0)$ & $3(6.1)$ \\
\hline Treatment type & $\mathrm{n}(\%):$ & & & \\
\hline Only chemo & & $19(30.2)$ & $3(21.4)$ & $16(32.7)$ \\
\hline $\mathrm{MC}$ & & $18(28.6)$ & $5(35.7)$ & $13(26.5)$ \\
\hline $\mathrm{EC}$ & & $5(7.9)$ & $1(7.2)$ & $4(8.2)$ \\
\hline Only excision & & $5(7.9)$ & $2(14.3)$ & $3(6.1)$ \\
\hline No therapy & & $16(25.4)$ & $3(21.4)$ & $13(26.5)$ \\
\hline
\end{tabular}

$\mathrm{n}=$ frequency, chemo = chemotherapy, $\mathrm{MC}=$ mastectomy and chemotherapy, $\mathrm{EC}=$ excision and chemotherapy. Values are presented as frequency (percentage). Statistical significant was not determined due to the zero frequencies.

Distribution of Haptoglobin phenotypes among studied population

Table 4 shows the various Hp phenotypes among patients compared with controls. Hp 1-1 and Hp 2-1 were significantly expressed in patients than controls $(\mathrm{p}<0.05)$ whiles Hp2-2 $\left(\chi^{2}=19.91, \mathrm{p}<0.001\right)$ was less expressed in the patients.

Table 4:- Distribution of Haptoglobin phenotypes among studied population.

\begin{tabular}{|c|c|c|c|c|c|c|c|}
\hline \multirow[b]{2}{*}{ Subjects } & & \multicolumn{4}{|c|}{ Haptoglobin phenotypes (Hp) } & \multicolumn{2}{|c|}{ HP allele frequency } \\
\hline & & Нp 1-1 & Hp 2-1 & Hp 2-2 & Нp 0 & HP 1 & HP 2 \\
\hline Patients $(\mathrm{N}=63)$ & $\mathrm{n}(\%)$ & $26(41.3)$ & $23(36.5)$ & $12(19.0)$ & $2(3.2)$ & 0.61 & 0.39 \\
\hline Control $(\mathrm{N}=54)$ & $\mathrm{n}(\%)$ & $10(18.5)$ & $12(22.2)$ & $27(50.0)$ & $5(9.3)$ & 0.33 & 0.67 \\
\hline$\chi^{2}$ & & 10.50 & 4.71 & 19.91 & 2.22 & 14.63 & 14.63 \\
\hline $\mathrm{P}$ & & $<0.005$ & $<0.05$ & $<0.001$ & $>0.05$ & $<0.001$ & $<0.001$ \\
\hline
\end{tabular}

$\mathrm{N}=$ sample size, $\mathrm{n}=$ phenotype frequency in the group

Hp 1-1 was significantly associated with breast cancer $(\mathrm{OR}=3.09, \mathrm{CI}=1.32-7.24, \mathrm{p}=0.014)$ than $\mathrm{Hp} 2-1(\mathrm{OR}=$ $2.1, \mathrm{CI}=0.88-4.58, \mathrm{p}=0.139)$ and $\mathrm{Hp} 2-2(\mathrm{OR}=0.24, \mathrm{CI}=0.10-0.54, \mathrm{p}=0.0008)$. However, haptoglobin phenotypes distribution showed no changes in the clinical parameters within the patients $(\mathrm{p}>0.05)$. Confounding analyses for BMI showed coefficients $\mathrm{B}=6.391, \mathrm{p}<0.001,95 \% \mathrm{CI}=3.381-9.402$, for chemotherapy when adjusted for age, haptoglobin phenotypes and blood pressure. Chemotherapy, unadjusted for age did not alter much of its effect on BMI $(\mathrm{B}=6.391, \mathrm{p}<0.000,95 \% \mathrm{CI}=3.516-9.367)$.

\section{Discussion:-}

Breast cancer $(\mathrm{BC})$ is a common cancer among women and is a major cause of cancer-related deaths. Breast cancer association with haptoglobin phenotypes $(\mathrm{Hp})$ is of great interest probably due to the poor prognosis of the disease and the variable antioxidant property of $\mathrm{Hp}$ phenotypes mediated by their respective molecular structures. Haptoglobin phenotype, Hp1-1 has far been associated with BC (Kaur et al., 1984; Bartel et al., 1985) and distribution of the phenotypes in a population was attributed to genetic and oxidative stress mechanism (Awadallah and Atoum, 2004). Furthermore, studies have also established strong association between Hp1-1 phenotype and other cancers (UGent et 
al., 2011; Nada et al., 2012). Conversely, a study reported no association between BC and Hp1-1 phenotype (Gast $e t$ al., 2008).

In this current study, BC patients of African descents, were found to highly express theHp1-1 phenotype than the control group (Table 4) and was strongly associated with the disease. However, Hp2-2 phenotype was poorly expressed in the patients whereas the degree of association of Hp2-1 phenotype with BC was between that of Hp1-1 and Hp2-1 phenotypes. The role of Hp1-1 phenotype in the development or progression of BC is not immediately known. However, the molecule may affect the tumour microenvironmental changes. Highly expressed Hp1-1 phenotype in patients may contribute to the antioxidant/oxidant disturbance in patients mentioned several years ago (Warburg, 1956). This occurrence may however, also explain the reported reduced oxidative stress characterized by lower lipid peroxidation in breast cancer patients than the apparently healthy controls (Gonenc et al., 2006). Lines of evidence have also shown association of overexpression of Hp1-1 with poor outcomes in oxidative stress-related disease (Quaye et al., 2000).

Patients also showed significantly elevated blood pressure (BP) and increased body mass index (BMI) (Table 1). Hypertension has strongly been associated with risk of BC and was pronounced in women with increased BMI (Largent et al., 2006). Women under hypertension treatment were also reported to be at risk of developing BC (Largent et al., 2010). Chemotherapy exposure has been reported to increase the risk of hypertension in patients (Fraema et al., 2013). However, no significant difference was noticed in the clinical indices when patients receiving chemotherapy were compared with the treatment naïve patients (Table 2). Intriguingly, patients receiving chemotherapy were found to show increased body mass index compared to their counterparts and this supports recent work (Ricci et al., 2014). Impact of increased body mass index on the health of breast cancer patients has received divergent views. Recently, increase in BMI of patients who were normal or underweight showed improved clinical outcomes in terms of pathological complete response (pCR) (Kogawa et al., 2015). In a different view, Chen et al., reported a negative impact of BMI on breast cancer treatment response in terms of pCR (Chen et al., 2012).

In summary, high prevalence of Hp1-1 in breast cancer patients does not differ among Ghanaians and this may suggest a critical role in the disease prognosis. Most of the patients were above 40 years and showed elevated blood pressure which may not necessarily be attributed to chemotherapy. Increase in BMI of patients on chemotherapy compared to those without treatment may suggest a possible effect of chemotherapy treatment on BMI. Here, age of patients was not a confounding factor.

\section{Conclusion:-}

In conclusion, our study reports for the first time the prevalence of hatoglobin phenotypes in Ghanaian breast cancer (BC) patients and the association of Hp 1-1 phenotype with the disease. The study also provided additional evidence of the impact of chemotherapy on blood pressure and BMI of BC patients with age not being a contributing factor. Further studies to associate haptoglobin phenotypes with $\mathrm{BC}$ prognosis may provide baseline information for disease prediction and management.

\section{Limitations of study:-}

The cross-sectional study did not consider baseline information for blood pressure and body mass index (BMI) of the participants. Additionally, determination of the duration of the disease was a challenge since most patients reported at the health facility with advanced tumour.

\section{Acknowledgement:-}

We thank the doctors, nurses and the entire paramedical staff at the Chemotherapy Unit of the Department of Surgery, Korle-Bu Teaching Hospital, Accra, Ghana. We are grateful to the staff of Dr. Manful Gwira's Laboratory, Department of Biochemistry, Cell and Molecular Biology, Legon, University of Ghana. We also thank our patients who volunteered to take part in the study. 


\section{Reference:-}

Abdullah, M., Schultz, H., Kähler, D., Branscheid, D., Dalhoff, K., Zabel, P., Vollmer, E. and Goldmann, T. (2009). Expression of the acute phase protein haptoglobin in human lung cancer and tumor-free lung tissues. Pathology Research and Practice. 205(9):639-47.

Awadallah, S. M. and Atoum, M. F. (2004). Haptoglobin polymorphism in breast cancer patients from Jordan. Clin. Chem Acta. 341(1-2):17-21.

Babita, R., Kumar, N., Karwasra, R. K., Singh, M., Malik, J. S. and Kaur, A. (2014). Reproductive risk factors associated with breast carcinoma in a tertiary care hospital of north India: A case-control study. Indian J Cancer. 51:251-5.

Bartel, U., Eling, D. and Gesserick, G. (1985). Distribution of Hp phenotypes in gynaecologic tumours. Zentralbl Gynakol. 107 (24): 1492-5.

Chen, S., Chen, C. M., Zhou, Y., Zhou, R. J., Yu, K. D., \& Shao, Z. M. (2012). Obesity or overweight is associated with worse pathological response to neoadjuvant chemotherapy among Chinese women with breast cancer. PloS One. 7(7): e41380.

Clegg-Lamptey J. N. A. and Hodasi, W. M. (2007). A study of breast cancer in Korle Bu Teaching hospital: assessing the impact of health education. Ghana Med J. 41(2):72-77

Fraeman, K. H., Nordstrom, B. L., Luo, W., Landis, S., H. and Shantakumar, S. (2013). Incidence of New-Onset Hypertension in Cancer Patients: A Retrospective Cohort Study. International Journal of Hypertension. 2013:379252.

Gast, M. C., Tinteren, H. van, Bontenbal, M., Hoesel, R. Q. van, Nooij, M. A., Rodenhuis, S., ... Beijnen,

J. H. (2008). Haptoglobin phenotype is not a predictor of recurrence free survival in high-risk primary breast cancer patients. BMC Cancer. 8; 389

Gerber, M., Astre, C., Segala, C., Saintot, M., Scali, J., Simony-Lafontaine, J., Grenier, J. and Pujol H. (1996). OxidantAntioxidant status alteration in cancer patients: relation to tumour progression. J. Nutri. 126:1201S-1207S.

Gonenc, A., Erten, D., Aslan, S., Akinci, M., Simsek, B. and Torun M. (2006). Lipid peroxidation and antioxidant status in blood and tissue of malignant breast tumour and benign breast disease. Cell Biology Int. 30: 376-380.

Ibrahim, N. E., Baleela, R. M. H., Elbashir, M. I., Ahmed, H. M., Elkhider I. and Elagib, A. A. (2012). Association of Hp 1-1 with liver disorders among Sudanese patients. Am. J. Sci. Ind. Res. 3(6): 403-405.

Jerby, L. Wolf, L., Denkert, C., Stein, G. Y., Hilvo, M., Oresic, M., Geiger, T., and Ruppin, E. (2012). Metabolic Associations of Reduced Proliferation and Oxidative Stress in Advanced Breast Cancer. Cancer Res. 72(22):1-10.

Kaur, H., Bhardwaj, D. N., Shrivastava, P. K., Sehajal, P. K., Singh, J. P., Paul, B. C. (1984). Serum protein polymorphisms in breast cancer. Acta Anthropog. 8:189-97.

Klaunig, J. E., Kamendulis, L. M. and Hocevar, B. A. (2010). Oxidative Stress and Oxidative Damage in Carcinogenesis. Toxicologic Pathology. 38: 96-109.

Kogawa, T., Fouad, T. M., Wei, C., Masuda, H., Kai, K., Fujii, T., El-Zein, R., Chavez-MacGregor, M., Litton, J. K., Brewster, A., Alvarez, R. H., Hortobagyi, G. N.,Valero, V., Theriault, R. and Ueno, N. T. (2015). Journal of Cancer. 6(4): 310-318.

Largent, J. A., McEligot, A. J., Ziogas, A., Reid, C., Hess, J., Leighton, N., Peel, D. and Anton-Culver, H. (2006). Hypertension, diuretics and breast cancer risk. Journal of Human Hypertension. 20:727-73.

Largent, J. A, Bernstein, L., Horn-Ross, P. L., Marshall, S. F., Neuhausen, S., Reynolds, P., Ursin, G., Zell, J. A., Ziogas, A. (2010). Anton-Culver H. Hypertension, antihypertensive medication use, and breast cancer risk in the California Teachers Study cohort. Cancer Causes Control. 21:1615-1624.

Maeda, N. (1991). DNA polymorphisms in the controlling region of the human haptoglobin genes: a molecular 
explanation for the haptoglobin 2-1 modified phenotype. Am J Hum Genet. 49(1):158-66.

Nada, E. I., Rania, M. H. B., Mustafa, I. E., Hussein, M. A., Isam, E. and Atif, A. E. (2012). Association of Hp 1-1 with liver disorders among Sudanese patients. Am J Sci and Indust Res. 3(6): 403

Nathan, C. and Ding, A. (2010). SnapShot: reactive oxygen intermediates (ROI). Cell. 140: 951.

Quaye, I. K, Ababio, G. and Amoah, A. G. (2006). Haptoglobin 2-2 phenotype is a risk factor for type 2 diabetes in Ghana. J Atheroscler Thromb. 13(2):90-4.

Quaye, I. K., Ekuban, F. A., Goka, B. Q., Adabayeri, V., Kurtzhals, J. A., Gyan, B., Ankrah N. A., Hviid L, Akanmori BD.(2000). Haptoglobin 1-1 is associated with susceptibility to severe Plasmodium falciparum malaria. Trans R Soc Trop Med Hyg. 94 (2):216-9.

Ricci, M. D., Formigoni, M. C., Zuliani, L. M., Aoki, D. S., Mota, B. S., Filassi, J. R., Piato, J. R. and Baracat, E. C. (2014). Variations in the body mass index in Brazilian women undergoing adjuvant chemotherapy for breast cancer. Rev Bras Ginecol Obstet. 36 (11):503-508

Sadrzadeh, S. M. and Bozorgmehr, J. (2004). Haptoglobin phenotypes in health and disorders. Am J Clin Pathol, 121, S97104.

UGent, R. S., Colebunders, B., Boelaert, J. R., UGent, L. B., Acker, J, V., UGent, F. V. W., Hemmer, R., UGent, M. S., UGent C. V., UGent, M. D. B., et al., (2011). Association of haptoglobin phenotypes with the development of Kaposi's sarcoma in HIV patients. Archives of Dermatological Research. 303(10):763-769

Vormittag, R., Vukovich, T., Mannhalter, C., Minar, E., Schönauer, V., Bialonczyk, C., Hirsch, M. and Pabinger, I. (2005). Haptoglobin phenotype 2-2 as a potentially new risk factor for spontaneous venous thromboembolism. Haematologica. 90(11):1557-61.

Warburg, O. (1956). On respiratory impairment in cancer cells. Science. 124: 269-270.

Zhao, C., Annamalai, L., Guo, C, Kothandaraman, N., Koh, S. C. L., Zhang, H., Biswas, A. and Choolani M. (2007). Circulating haptoglobin is an independent prognostic factor in the sera of patients with epithelial ovarian cancer. Neoplasia. 9(1): 1-7. 